\title{
Editorial
}

\section{Community hospitals: a desirable option?}

Community hospitals could be viewed as a desirable option in inner cities, especially in caring for the growing population of elderly people. This is important in view of comparative lack of geriatric hospital beds and provision of nursing homes in inner cities. ${ }^{1}$ There is also evidence of high patient satisfaction within existing centres - for example, the Paddington Community Hospital and the Lambeth Community Care Centre and this is also reflected in the article in this issue by Sally Hull and Ian Jones (p 214). ${ }^{2}$ They have explored general practitioners' views in Tower Hamlets, London, a very deprived area with a large number of ethnic groups and high deprivation levels.

\section{Added commitment of community hospitals}

The question of overriding importance, however, is whether general practitioners in inner city areas can take on the added commitment entailed in looking after their patients in community hospitals. Doctors in deprived areas are already overloaded, trying to cope with existing responsibilities, including added duties imposed in the 1990 Contract for General Practice. A recent national survey of $10 \%$ of general practitioners conducted for the Royal College of General Practitioners inner city task force within the department of general practice at St Mary's Hospital disclosed that respondents in severely deprived areas list "lack of time and overwork" as important obstacles to providing a good service for patients. $^{3}$ The most popular suggestion in the survey for improvement in primary care for inner city populations was an extension of the primary care team, including more "experts," such as legal and social security advisors, but there was very little reference to community hospitals and their possible benefits.

There is need to look critically at reports of the Lambeth and Paddington community hospitals. In my view, there is a natural division between the hospital and the community, and general practitioners belong to the community sector. Hospital doctors are best qualified to deal with work in the hospital part of the health service and probably do so more cost effectively, unless general practitioners are being used as a cheap alternative.

\section{Expending development of community hospitals}

In view of the current workload carried by inner city general practitioners, large scale development of community hospitals as a "midway" option between home care and traditional hospital care must be regarded with healthy scepticism. There would be need for an extensive survey of general practitioners' opinion in inner city areas throughout the country to explore general views about the community hospital concept and the ability to take on this additional responsibility, before any extension of this development. There has been a tendency to concentrate on London in discussion about problems of inner city deprivation and their solution, in terms of health service provision. It is essential to explore overall inner city healthcare provision, drawing on data from a cross section of similar areas throughout the country. Degree of reliance on multidisciplinary teamwork is clearly an important point in assessing the feasibility of community hospitals. Nurse practitioners have been recognised as performing a useful complementary role to that of the general practitioner in a recent survey carried out within Kensington and Chelsea and Westminster Health Commissioning Agency. ${ }^{4}$ There is anecdotal evidence that patients find the services provided by nurse practitioners satisfactory, but consultation times tend to be longer than those normally allocated in general practice.

Any decision to extend development of community hospitals would depend on several important factors including available resources, degree of commitment to the scheme by health professionals, and patient preference. The need to ensure that adequate resources for developments of this kind are available cannot be overemphasised. Hull and Jones make the important point that finding "capital funds for community hospitals should not conflict with improvements to GP surgery premises." This is clearly a fundamental point, which must be appreciated by those responsible for allocating resources.

Professor of Primary Health Care, Department of General Practice, St Mary's Hospital Medical School, London W2 $1 P G$

Jarman B. The crisis in London medicine: how many hospital beds does the Capital need? Special University Lecture, University of London, 1994. Hull SA, Jones I. Is there a demand among general practitioners for inner city community hospitals? Quality in Health Care 1995;4:214-7. Lorentzon M, Jarman B, Bajekal M. Report of the Inner City Task Force orentzon M, Jarman B, Bajekal M. Report of the Inner City Task
of the Royal College of General Practitioners. London: RCGP, 1994.

4 Kensington and Chelsea and Westminster Health Commissioning Agency. Nurse practitioners in Kensington and Chelsea and Westminster: a position paper. London: KCWHCA, 1994. 